\title{
Fire development study on physical models of transport tunnels
}

\author{
Omar Lanchava ${ }^{1,2^{*}}$, Nicolae Ilias ${ }^{3}$, Sorin Mihai Radu³, Marad Jangidze ${ }^{1}$, and Zaza \\ Khokerasvili $^{2}$ \\ ${ }^{1}$ G. Tsulukidze Mining Institute, Tbilisi, Mindeli Street 7, Georgia \\ ${ }^{2}$ Georgian Technical University, Tbilisi, Kostava Street, 77, Georgia \\ ${ }^{3}$ University of Petroşani, Petroşani, Universităţii Street 20, Romania
}

\begin{abstract}
The work gives the study results for 1:10 scale physical models of the road tunnels. The tunnel slope changes from 0 to $10 \%$ with a $2 \%$ spacing. As the models show, the fire strength varies within the range of 5 to $15 \mathrm{MW}$ with $5 \mathrm{MW}$ increments. The properties of the tunnel geometry in nature are as follows: cross-sectional area: $46.7 \mathrm{~m}^{2}$, length: $120 \mathrm{~m}$, width: $8.5 \mathrm{~m}$, height: $5.5 \mathrm{~m}$ and width and height ratio: 1.54 . The models are made of $2 \mathrm{~mm}$-thick stainless-steel sheets. We studied the nature of the spread of smoke, the variation of critical velocity depending on the tunnel slope and the characteristic value of such variation - the grade correction factor. The observation over such values is done depending on the air temperature variability in the tunnel model. The measurements are made with K-type thermocouples with open and closed detectors. Maximum temperature measurement is $800^{\circ} \mathrm{C}$. The thermocouples are located in the holes provided in the ceiling of the tunnel model. The distance between the holes is 5 and $10 \mathrm{~cm}$ what corresponds to the natural length of the tunnel of 5 and $10 \mathrm{~m}$. Fire is modeled by using the natural gas. The indications of thermocouples and air and gas meters are measured simultaneously and the primary analysis and the digital data transmission are provided with a Data Taker DT85 data logger. The gained results may be used to develop ventilation and emergency management projects for transport tunnels as well as to train personnel and rescuers.
\end{abstract}

\section{Introduction}

The critical velocity of ventilation and the opposite diffusion of smoke in the fresh air current (backlayering) are important technological values in ventilation projects that determine the ventilation efficiency. Within the scope of emergency management projects, these values are of a paramount importance because their prediction is necessary to solve evacuation and firefighting problems. If $\mathrm{u}_{0}(\mathrm{~m} / \mathrm{s})$ is the velocity of the linear ventilation and $u_{c}(\mathrm{~m} / \mathrm{s})$ is the critical velocity of the linear ventilation, then the case when $u_{0}>u_{c}$ is the technological means to exclude backlayering. These values were introduced as semiempirical formulas by Thomas [1]. Depending on the tunnel slope, these values vary. The

${ }^{*}$ Corresponding author: o.lanchava@yahoo.com 
rate of variation, depending on the inclination, is the grade correction factor - grade correction factor $\left(\mathrm{k}_{\mathrm{g}}\right)$. Consequently, the prediction of the critical velocity and backlayering length using the grade correction factor is done according to well-studied fire spread scenarios in the horizontal tunnels. The asymmetrical spread of the combustion products towards the fire hearth is particularly evident when the tunnel is a sloping one and the fresh air inlet has a greater hypsometrical height than the fire hearth.

The present study results consider the worst scenarios of the given type of longitudinal ventilation of spread of harmful combustion factors. The essence of the problem is to determine the regularities of the variation of the air current aerodynamics and important technological parameters of ventilation in the tunnel under the fire impact, when the tunnel slope and heat release rate vary and the tunnel aerodynamics is complicated in case of transformable batteries as additional barriers, which must be viewed as a useful device to increase the evacuation time.

The work gives the study results for 1:10 scale physical models of the road tunnels. The tunnel slope changes from 0 to $10 \%$ with a $2 \%$ spacing. The fire strength varies within the range of 5 to $15 \mathrm{MW}$ with $5 \mathrm{MW}$ increments. The models are made of $2 \mathrm{~mm}$-thick stainlesssteel sheets. The cross section of the model is $0.467 \mathrm{~m} 2$; its length is $12 \mathrm{~m}$; its width is: 0.85 $\mathrm{m}$; its height is $0.55 \mathrm{~m}$ and its width and height ratio are 1.54 .

We studied the nature of the spread of smoke, the variation of critical velocity depending on the tunnel slope and the characteristic value of such variation - the grade correction factor. The observation over such values is done depending on the air temperature variability on the tunnel model. The values are measured with K-type thermocouples with open and closed detectors. The maximum temperature possible to measure with thermocouples is $800^{\circ} \mathrm{C}$. The thermocouples are located in the holes made in the ceiling of the tunnel model. The distance between the holes is 5 and $10 \mathrm{~cm}$ what corresponds to the natural length of the tunnel of 5 and $10 \mathrm{~m}$. Fire is modeled by using the natural gas. The air is supplied to the model with axial fans having appropriate power. The sensitivity range of air velocity meter is $6-75 \mathrm{~m} / \mathrm{s}$. The indications of thermocouples and meters are measured simultaneously and the primary analysis and the digital data transmission are provided with a Data Taker DT85 data logger.

The gained results may be used to develop ventilation and emergency management projects for transport tunnels as well as to train personnel and rescuers.

\section{Theory}

The Froude Number modeling strategy is widely used in fire experiments. The essence of this strategy is that the Froude Number, which characterizes the forces of inertia and floating, will be directly maintained in the physical models. The Froude Number calculation formula is as follows:

$$
F r_{c}=\frac{\Delta p g H}{\rho_{0} u_{c}^{2}}
$$

The values given by the formulas and used in the present article are defined in Table 1.

Table 1. Definition and dimensions of the values given in the formulas.

\footnotetext{
A - tunnel cross-sectional area $\left(\mathrm{m}^{2}\right)$;

$\mathrm{c}_{\mathrm{p}}$ - specific heat of air $(\mathrm{kJ} /(\mathrm{kg} . K)$;

$\mathrm{Fr}_{\mathrm{c}}$ - critical Froude Number;

$\mathrm{G}_{\mathrm{m}}$ - mass air flow;

$\mathrm{g}$ - gravitational acceleration $\left(\mathrm{m} / \mathrm{s}^{2}\right)$;
} 


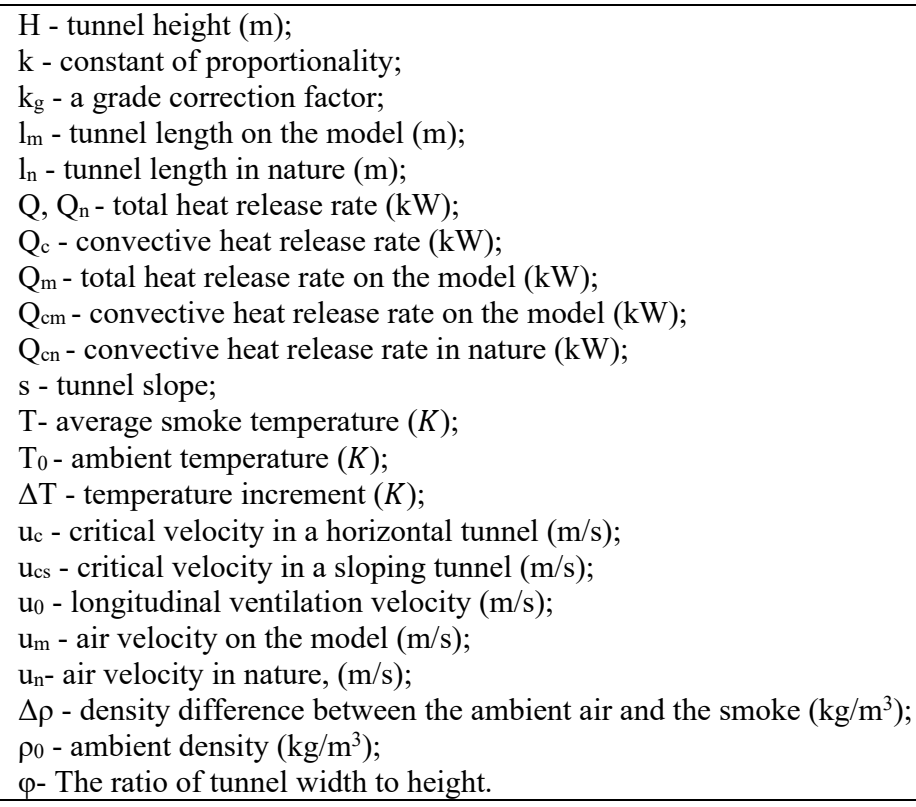

With Froude Number modeling, the temperature field is the same and the heat release scale and ventilation rate are characterized by a geometrical scale by using the following formulas

$$
\begin{aligned}
& \frac{Q_{m}}{Q_{n}}=\left(\frac{l_{m}}{l_{n}}\right)^{2.5} \\
& \frac{u_{m}}{u_{n}}=\left(\frac{l_{m}}{l_{n}}\right)^{0.5}
\end{aligned}
$$

One must note the convenience of using the Froude Number to study the problem by means of physical modeling on the one hand, and the little accuracy when using the critical Froude Number on the other hand what is described in reference $[2,3]$. The idea of using the critical Froude Number implies rapid mixing of equal amounts of flue gases and fresh air at the hearth of the fire, what is not always the case, particularly when the width of the tunnel carriageway significantly exceeds its height. Consequently, the geometry of the tunnel determines the use of the Froude criterion. It is therefore important to know when it is possible to use the Froude Number and in addition, if necessity, if we can assume that when different ratios of clean and polluted air are mixed at the hearth of fire, what kind of correlation will be and if the Froude Number is applicable.

For horizontal tunnels, the critical velocity is calculated by formula:

$$
u_{c}=k\left(\frac{g \dot{Q}_{c} H}{\rho_{0} c_{p} T A}\right)^{1 / 3}
$$

The constant of proportionality in formula (4) is determined by the critical Froude Number

$$
k=F r_{c}^{-1 / 3}
$$


Danziger and Kennedy [4] expected that like in case of Reynolds Number, the Froude Number would have a critical value and set 4.5 as its critical value. At this point, we would only note that the idea of the critical Froude Number facilitates the issue, as in this case, in formula (4) coefficient $k=0.606$ what is hardly true with the justification of the said idea.

The convective heat released during the fire is calculated with formula:

$$
\dot{Q}_{c}=\rho_{0} c_{p} u_{0} A \Delta T
$$

The convective heat making $70 \%$ of the total head amount can be calculated with formula:

$$
\dot{Q}_{c}=0.7 \dot{Q}
$$

Average smoke temperature is calculated with formula:

$$
T=T_{0}+\frac{\dot{Q}_{c}}{\rho_{0} c_{p} A u_{c}}
$$

The paper [5] studied the fire caused by the wood blockage sized $0.3 \times 0.3 \times 10 \mathrm{~m}$ in the aerodynamic pipe and stated that the aerodynamic resistance of the tunnel at the fire hearth increased 6-fold for the ventilation current and by about 1.5 times beyond the fire, on both sides of it. The strong impact of fire on the aerodynamic processes in tunnels, as well as on the algebraic convergence of dynamic pressures induced by fire and developed by fans is mentioned in paper [6].

As per the results of the experiments, the numerical values of the grade correction factor depending on the tunnel slope can be determined by formula:

$$
k_{g}=\frac{u_{c s}}{u_{c}}
$$

Dimensionless back layering length and dimensionless critical velocities are determined by following formulas $[2,3]$ :

$$
L_{b}^{*}=\frac{L_{b}}{H}=18.5 \ln \left(u_{c s} / u_{c}\right)
$$

For horizontal tunnels:

$$
\begin{gathered}
u_{c}^{*}=\frac{u_{c}}{\sqrt{g H}}=0.81 \varphi^{-1 / 12} Q^{* 0.33}, \text { when } Q^{*} \leq 0.15 \varphi^{-1 / 4} \\
u_{c}^{*}=\frac{u_{c}}{\sqrt{g H}}=0.43, \text { when } Q^{*}>0.15 \varphi^{-1 / 4}
\end{gathered}
$$

For sloping tunnels:

$$
\begin{gathered}
u_{c}^{*}=\frac{u_{c}}{\sqrt{g H}}=0.81\left(1+0.014 \tan ^{-1}(s / 100)\right) \varphi^{-1 / 12} Q^{* 0.33}, \text { when } Q^{*} \leq 0.15 \varphi^{-1 / 4} \\
u_{c}^{*}=\frac{u_{c}}{\sqrt{g H}}=0.43\left(1+0.014 \tan ^{-1}(s / 100)\right), \text { when } Q^{*}>0.15 \varphi^{-1 / 4}
\end{gathered}
$$

Where the heat release dimensionless value and the ratio between the tunnel width and length are determined by formula: 


$$
\begin{gathered}
Q^{*}=\frac{\dot{Q}}{\rho_{0} c_{p} T_{0} g^{0.5} H^{2.5}} \\
\varphi=\frac{W}{H}
\end{gathered}
$$

According to the ideal gas law, the density ratio may be changed by the relevant temperature ratio. Then, formula (1) will be as follows

$$
F r_{c}=\frac{\Delta \rho g H}{\rho_{0} u_{c}^{2}}=\frac{\Delta T g H}{T u_{c}^{2}}
$$

\section{Results and Discussion}

The aim of experiment is to simulate various scenarios of fire distribution across the modeled tunnel, develop effective mechanisms for safety purposes and extension of time required for evacuation. The data controlling and logging system should be setup in order to conducting experiments, the system should collect data from various sensors and controllers and $\log$ them in the internal memory for farther analyzes of collected data.

As already mentioned, during the experiments, the tunnel slope varies from $0-10 \%$ with a $2 \%$ spacing. This is done with the tunnel lifting and fixing devices. The tunnel model fixed in a horizontal position is given in Figure 1.

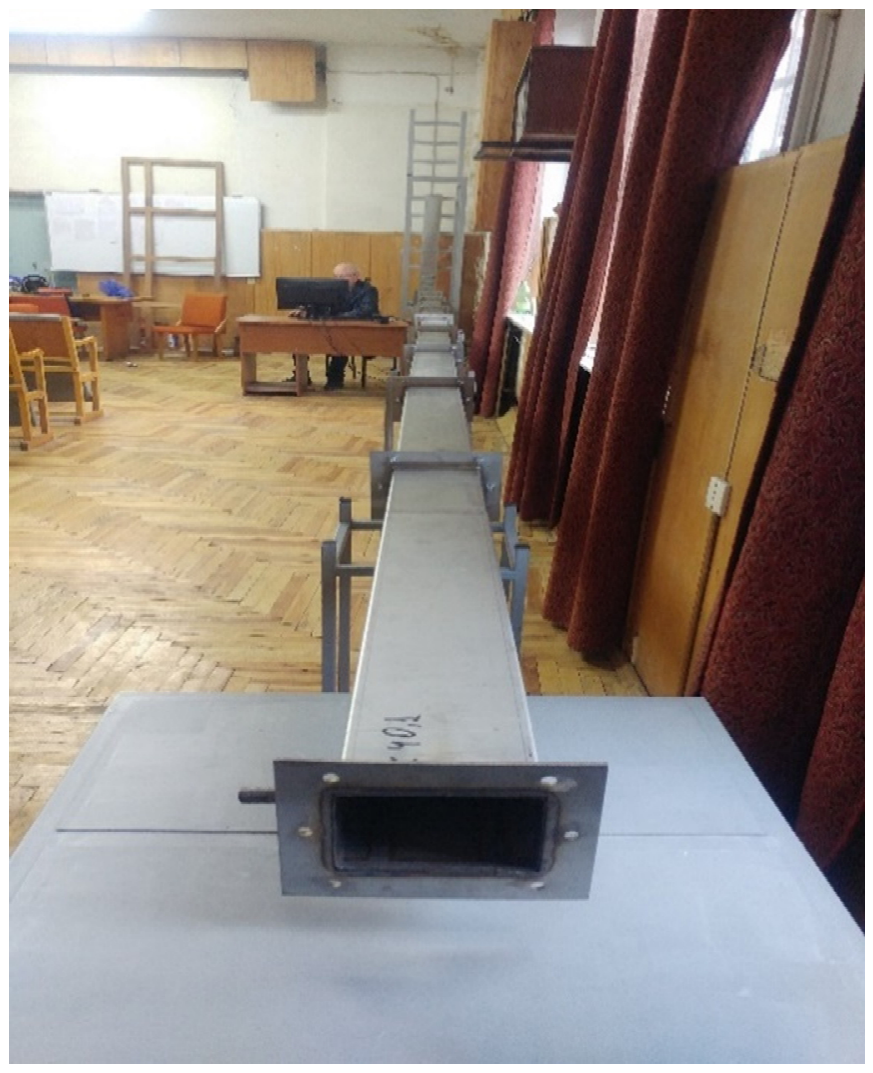

Fig. 1. The tunnel model fixed in a horizontal position: the background shows the lifting mechanism and the foreground shows the tunnel cross section, which must be connected to the inlet air duct. 
The monitoring system consists of a central DAT85 data collection module manufactured by Data Taker and 4 types sensors connected to it. Namely, there are two types of the Thermocouples, duct mounted air velocity transmitter and Mass Flow Controller. System should control gas flow, measure and log the air velocity and temperature change across the modeled tunnel.

Technical parameters of the system components are as follows:

K Type Thermocouple with open end sensor - Cable cross-section area $-0.2 \mathrm{~mm}^{2}$, Cable Length - 1m; Sensor Diameter - 0.51mm; Sensor Shield - No Shield, Open end Sensor;

K Type Thermocouple Insulated Sensor - Cable cross-section area $-0.2 \mathrm{~mm}^{2}$, Cable Length - 1m; Sensor Diameter - 3mm; Sensor Shield - Shielded/insulated sensor, grounded with hot termination;

Mini onnector Type K Male - Type SMPW;

Mini onnector Type K Female - Type SMPW;

Mass and volumetric flow controller -The mass and volumetric flow controller with LCD display working using the principle of differential pressure for determinate and control of mass flow rate. Controller should display gas pressure, volumetric and mass flow rate and temperature on the LCD display. With pushbutton interface selectable gas calibrations for over 100 types of pure and mixed gases. Accuracy: - $\pm 0.8 \%$; Response Time- $100 \mathrm{~ms}$; I/O Signal - 4-20 mA; Operating Temperature - from -10 to $+50{ }^{\circ} \mathrm{C}$; Measurement Range - 0.5 - $500 \mathrm{~cm}^{3} / \mathrm{min}$; Integrated Sensors - Absolute Pressure Sensor, Differential Pressure Sensor, Temperature Sensor.

Air Velocity Transmitter - Working Range - 0.2 - $10 \mathrm{~m} / \mathrm{s}$; Accuracy - $\pm 0.2 \mathrm{~m} / \mathrm{s}$; Response Time - $1 \mathrm{sec}$; Analog Output - 4-20 mA; Probe Length - $100 \mathrm{~mm}$.

The physical modeling of the experiment scaled 1:10: model cross section: $0.85 * 0.55=$ $0.467 \mathrm{~m}^{2}$; cross section in nature: $8.5 * 5.5=46.7 \mathrm{~m}^{2}$; linear scale of modeling: $1: 10=0.1$.

As Formula (2) shows, the heat modeling scale will be:

$$
\frac{\dot{Q}_{m}}{\dot{Q}_{n}}=\left(\frac{l_{m}}{l_{n}}\right)^{2.5}=\left(\frac{12}{120}\right)^{2.5}=0.00316
$$

From last formula $\dot{Q}_{m}=0.00316 \dot{Q}_{n}$.

The amount of convective heat in nature increases and it is $70 \%$ of the total heat amount on the model. $1 \mathrm{~m}^{3}$ natural gas gives out $9,3 \mathrm{~kW}$ heat energy when it burns. The values calculated based on the given indicators are given in Table 2 .

Table 2. The ratio of the fire heat release rate on the model and in nature for the given scale.

\begin{tabular}{|c|c|c|c|c|}
\hline \multicolumn{2}{|c|}{$\begin{array}{c}\text { Total fire strength, linear scale: } \\
\mathbf{1 : 1 0 ,} \text { in nature and on the model }\end{array}$} & \multicolumn{2}{c|}{$\begin{array}{c}\text { Fire convective component in } \\
\text { nature and on the model }\end{array}$} & $\begin{array}{c}\text { Natural gas } \\
\text { consumption, } \\
\mathbf{m}^{\mathbf{3}} / \mathbf{h}\end{array}$ \\
\hline $\mathbf{Q} \mathbf{\mathbf { n }}, \mathbf{M W}$ & $\mathbf{Q}_{\mathbf{m}}, \mathbf{k W}$ & $\mathbf{Q} \mathbf{\mathbf { c n }}, \mathbf{M W}$ & $\mathbf{Q}_{\mathbf{c m}}, \mathbf{k W}$ & 1.7 \\
\hline 5 & 15.8 & 3.5 & 11.1 & 3.4 \\
\hline 10 & 31.6 & 7.0 & 22.2 & 5.1 \\
\hline 15 & 47.4 & 10.5 & 33.3 & \\
\hline
\end{tabular}

As per formula (3), the scale of ventilation velocity modeling will be as follows

$$
\left(\frac{u_{m}}{u_{n}}\right)=\left(\frac{l_{m}}{l_{n}}\right)^{0.5}=\left(\frac{12}{120}\right)^{0.5}=0.316
$$

Thus $u_{m}=0.316 u_{n}$. 
The results of air velocity calculations in nature and on the model and the values measured for the model fires of different strengths are given in Table 3.

Table 3. Air velocity ratio on the model and in nature for the given scale.

\begin{tabular}{|c|c|c|c|c|c|}
\hline \multicolumn{2}{|c|}{$\begin{array}{l}\text { Air velocity in nature } \\
\text { and on the model }\end{array}$} & \multirow{2}{*}{$\begin{array}{c}\text { Mass air } \\
\text { consumption } \\
\text { on the model, } \\
\mathbf{G}_{\mathrm{m}}, \mathrm{kg} / \mathrm{h}\end{array}$} & \multicolumn{3}{|c|}{$\begin{array}{l}\text { Temperature increment on the model } \\
\text { relevant to the fire strength in the nature, }{ }^{\circ} \mathrm{C}\end{array}$} \\
\hline $\mathbf{u}_{\mathbf{n}}, \mathbf{m} / \mathbf{s}$ & $\mathbf{u}_{\mathbf{m}}, \mathbf{m} / \mathbf{s}$ & & $5 \mathrm{MW}$ & $10 \mathrm{MW}$ & 15 MW \\
\hline 0.5 & 0.158 & 318.7 & 178.5 & 356 & 535 \\
\hline 1.0 & 0.316 & 637.4 & 89.2 & 178 & 267 \\
\hline 1.5 & 0.474 & 956.1 & 59.5 & 120 & 180 \\
\hline 2.0 & 0.632 & 1274.8 & 44.6 & 89 & 134 \\
\hline 2.5 & 0.790 & 1593.5 & 35.7 & 71 & 106 \\
\hline
\end{tabular}

The critical velocity variation on the models of the horizontal and sloping tunnels when the fire convection component $\left(\dot{Q}_{c m}\right)$ is $11.1,22.2$ and $33.3 \mathrm{~kW}$, are given in Figure 2, while the critical velocity variation for the horizontal and sloping tunnels for 5, 10, and $15 \mathrm{MW}$ fires is given in Figure 3.

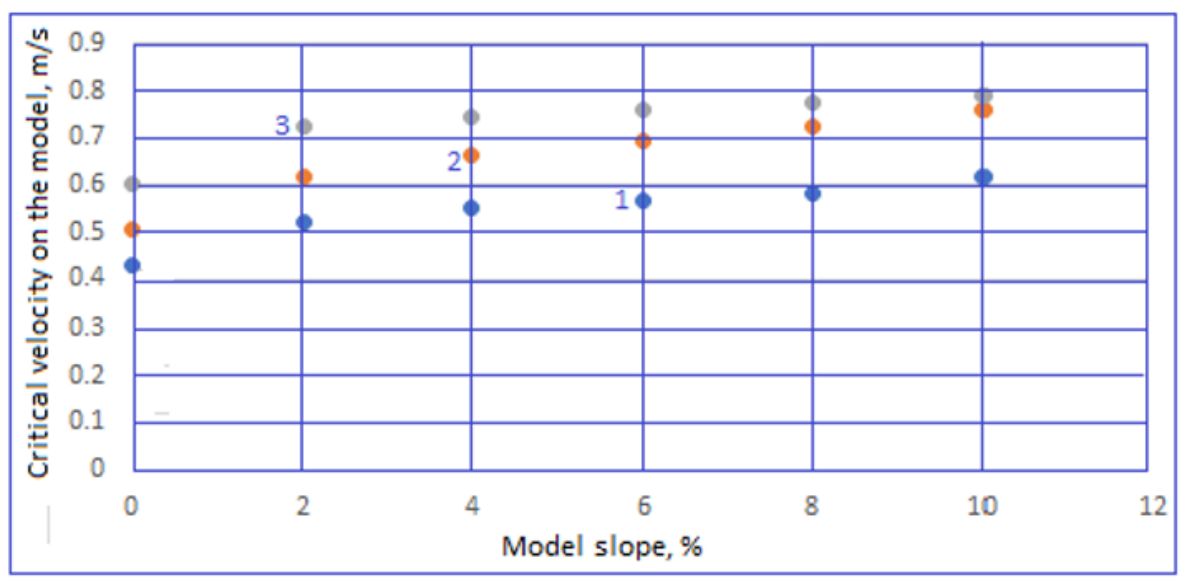

Fig. 2. Critical velocity variation depending on the model slope for the modeled fire of different strengths: $1-15.8 \mathrm{~kW} ; 2-31.6 \mathrm{~kW} ; 3-47.4 \mathrm{~kW}$.

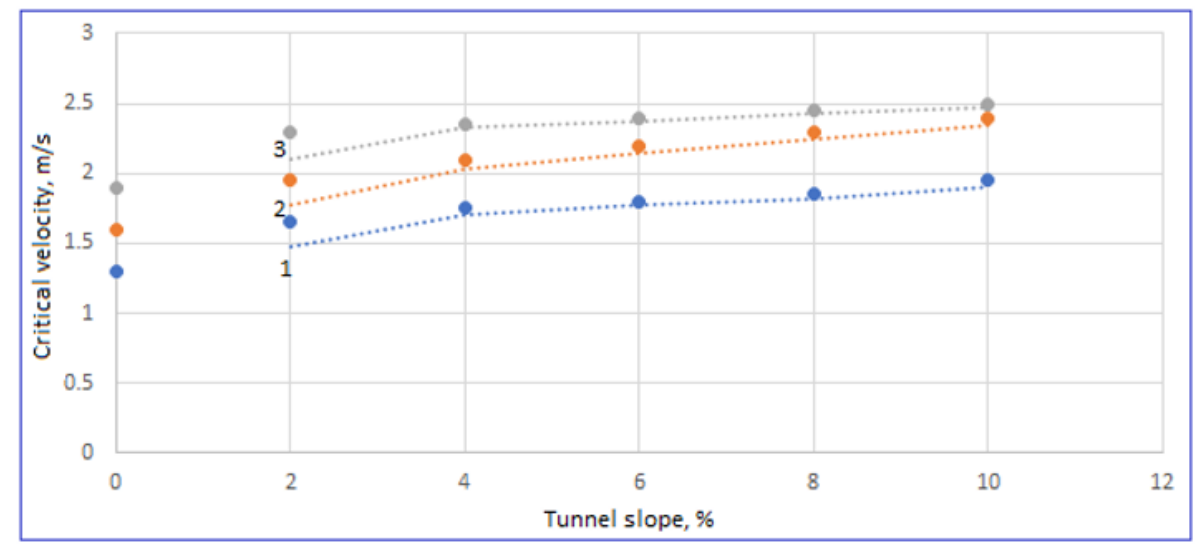

Fig. 3. Critical velocity variation depending on the tunnel slope in terms of fires of different strengths: 1 - $5 \mathrm{MW} ; 2$ - $10 \mathrm{MW}$; 3 - $15 \mathrm{MW}$. 
One must note the little sensitivity of equation (4) to temperature variation when calculating the critical velocities. To illustrate this, let us use formula (4) to calculate the critical velocity $\mathrm{u}_{\mathrm{cm}}$ for a $5 \mathrm{MW}$ modeled fire in nature on the model of tunnel according to the corresponding values given in Tables 2 and 3.

$$
u_{c m}=0.606 *\left(\frac{9.8 * 11.1 * 0.55}{0.779 * 1.022 * 471.7 * 0.467}\right)^{0.33}=0.606 *\left(\frac{59.829}{175.1}\right)^{0.33}=0.425 \approx 0.43 \mathrm{~m} / \mathrm{s}
$$

Here, average smoke temperature is $\mathrm{T}=273,2+20+178.5=471.7 \mathrm{~K}$, and $20^{\circ} \mathrm{C}$ is ambient temperature.

For the temperature $\mathrm{T}=471.7 \mathrm{~K}: \rho_{0}=0.779 \mathrm{~kg} / \mathrm{m}^{3} ; \mathrm{c}_{\mathrm{p}}=1.022 \mathrm{~kJ} /(\mathrm{kg} . \mathrm{K})$ [7].

For the gained critical velocity $\left(\mathrm{u}_{\mathrm{cm}}=0.43 \mathrm{~m} / \mathrm{s}\right)$, let us specify the average smoke temperature with formula (8)

$$
T=T_{0}+\frac{\dot{Q}_{c}}{\rho_{0} c_{p} A u_{c m}}=293,2+\frac{11.1}{0.779 * 1.022 * 0.467 * 0.43}=362.6 \mathrm{~K}
$$

And now, according to the specified temperature $(\mathrm{T}=362.6 \mathrm{~K})$, let us re-calculate the critical velocity $\left(\mathrm{u}_{\mathrm{cm}}\right)$ with formula (4)

$$
u_{c m}=0.606 *\left(\frac{9.8 * 11.1 * 0.55}{1.029 * 1.009 * 362.6 * 0.467}\right)^{0.33}=0.606 *\left(\frac{59.829}{175.8}\right)^{0.33}=0.4246 \approx 0.43 \mathrm{~m} / \mathrm{s} .
$$

For the temperature $T=362.6 K: \rho_{0}=1.029 \mathrm{~kg} / \mathrm{m}^{3} ; c_{p}=1.009 \mathrm{~kJ} /(\mathrm{kg} . K)[7]$.

The temperature is calculated based on the latter velocity $u_{c m}=0.43 \mathrm{~m} / \mathrm{s}$ is $T=356.4 K$.

$$
T=293,2+\frac{11.1}{1.029 * 1.009 * 0.467 * 0.43}=356.4 \mathrm{~K}
$$

So, we can say that in nature, for the fire with heat release rate of $\dot{Q}_{n}=5 \mathrm{MW}$, with corresponding $\dot{Q}_{c m}=11.1 \mathrm{~kW}$ convective components on the model, the critical velocity for the horizontal tunnel model is $u_{c m}=0.43 \mathrm{~m} / \mathrm{s}$. We gain this result when the average smoke temperature is $T=471.7 \mathrm{~K}$ and when the same temperature is $T=356.4 \mathrm{~K}$. Consequently, formula (4) responds to temperature rise $\Delta T=115 \mathrm{~K}$ insignificantly. It is possible not to take the given temperature increase into account. As for the formula, it is less sensitive. Therefore, the view found in the scientific literature $[2,3]$ regarding the critical Froude Number needs further scrutiny.

In a tunnel of a real scale, the calculation of the critical velocity for the fire with heat release rate $\dot{Q}_{n}=5 \mathrm{MW}$ is possible with formula (3) according to the scale of velocity modeling defined above and it is $u_{c}=1.36 \mathrm{~m} / \mathrm{s}$.

We give similar calculations without definitions in nature for a fire with $\dot{Q}_{n}=10 \mathrm{MW}$ heat release rate with corresponding convectional component on the model of strength $\dot{Q}_{c m}=22.2 \mathrm{~kW}$.

By using formula (4),

$$
\begin{gathered}
u_{c m}=0.606 *\left(\frac{9.8 * 22.2 * 0.55}{0.566 * 1.058 * 649.2 * 0.467}\right)^{0.33}=0.606 *\left(\frac{119.7}{173.6}\right)^{0.33}=0.536 \approx 0.5 \mathrm{~m} / \mathrm{s} . \\
T=273,2+20+356=649.2 \mathrm{~K} \\
T=T_{0}+\frac{\dot{Q}_{c}}{\rho_{0} c_{p} A u_{c m}}=293,2+\frac{22.2}{0.566 * 1.058 * 0.467 * 0.5}=452.0 \mathrm{~K}
\end{gathered}
$$

let us calculate the critical velocity on model $\left(u_{c m}\right)$ according to temperature $T=452.0 \mathrm{~K}$ : 


$$
u_{c m}=0.606 *\left(\frac{9.8 * 22.2 * 0.55}{0.815 * 1.017 * 452 * 0.467}\right)^{0.33}=0.606 *\left(\frac{119.7}{175}\right)^{0.33}=0.53 \approx 0.5 \mathrm{~m} / \mathrm{s} .
$$

Now, let us calculate the temperature, which corresponds to the gained critical velocity $u_{c m}=0.5 \mathrm{~m} / \mathrm{s}$ :

$$
T=T_{0}+\frac{\dot{Q}_{c}}{\rho_{0} c_{p} A u_{c m}}=293,2+\frac{22.2}{0.815 * 1.017 * 0.467 * 0.5}=407.9 \mathrm{~K} .
$$

Now, let us calculate $u_{c m}$ according to latter temperature value of $T=407.9 \mathrm{~K}$ :

$$
u_{c m}=0.606 *\left(\frac{9.8 * 22.2 * 0.55}{0.922 * 1.009 * 407.9 * 0.467}\right)^{0.33}=0.606 *\left(\frac{119.7}{177}\right)^{0.33}=0.53 \approx 0.5 \mathrm{~m} / \mathrm{s}
$$

Thus, in nature, for the fire with $\dot{Q}_{n}=10 \mathrm{MW}$ heat release rate, with corresponding convectional component on the model of strength $\dot{Q}_{c m}=22.2 \mathrm{~kW}$, the critical velocity for a horizontal tunnel model is $u_{c m}=0.5 \mathrm{~m} / \mathrm{s}$, while the above-mentioned negligible sensitivity of formula (4) to the temperature variation is still the case. The critical velocity for the fire with $\dot{Q}_{n}=10 \mathrm{MW}$ heat release rate in a horizontal tunnel of a real scale is $u_{c}=1.6 \mathrm{~m} / \mathrm{s}$.

As per the gained results, the averaged numerical values of grade correction factor defined for fires with the strength of 5-15 MW are given in Figure 4.

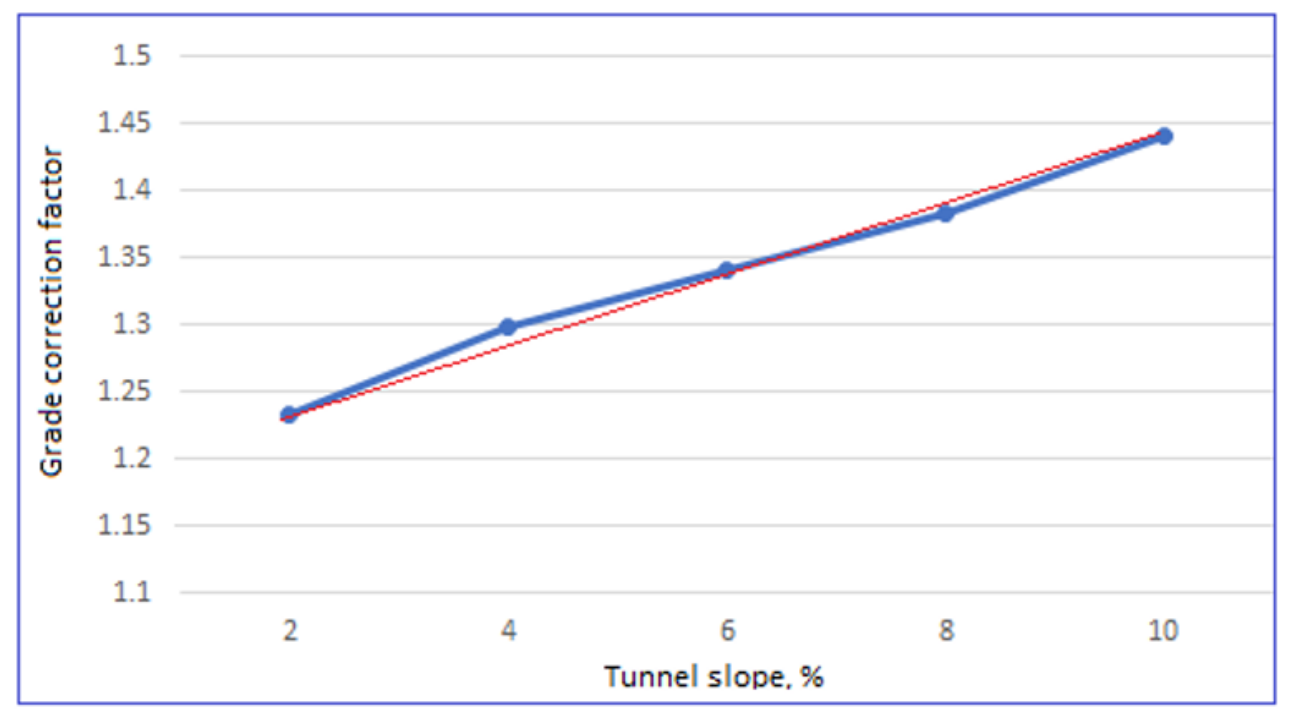

Fig. 4. The variation of the averaged numerical values of grade correction factor depending on sloping.

As the given drawing shows, the course of the averaged grade correction factor within the range of $2-10 \%$ slope is in fact linear (see the additional red line in Fig. 4).

\section{Conclusion}

The given paper studies the critical velocity and indicator of its variation rate - the grade correction factor on the physical models of the horizontal and slopping tunnels. The models were made with 2 -mm-thick stainless-steel sheets. The sloping gradient was $0-10 \%$ with a $2 \%$ spacing. The fire was modeled by using the natural gas and its heat release rate was 5 , 
10 and $15 \mathrm{MW}$. The results show that the famous formula to calculate the critical velocity given in the present work as formula (4), responds to the temperature rise insignificantly and is less sensitive in this regard. The paper gives the regularities of critical velocity and grade correction factor variations as diagrams, which are valid for differently sloping tunnels and can be applied to define the critical velocity and back layering length, as well as to realize the ventilation and emergency response project.

This work was supported by Shota Rustaveli National Science Foundation (SRNSF) [Grant number AR-19-1936, Project title "Development and testing of transformable system to save life in road tunnel in case of fire"].

Special thanks to Karthik Vilvanathan at Thermo Fisher Scientific for his affords and great support for finding the ways for delivery and support of DataTaker DT85 to Georgia. DT85 was the central part of the testing system in the modeled tunnel responsible for data collection and analyzes.

\section{References}

1. P.H. Thomas, Fire Research Notes 351, Available on http://www.iafss.org/publications/frn/351/$\underline{1}$

2. Y.Z. Li, H. Ingason, and L. Jiang, Influence of tunnel slope on smoke control (RISE Research Institutes of Sweden, 2018)

3. Y.Z. Li, and H. Ingason, Fire Safety Journal 99, 22-26 (2018)

4. N.H. Danziger, and W.D. Kennedy, $4^{\text {th }}$ International Symposium on the Aerodynamics \& Ventilation of Vehicle Tunnels, 169-186 (1982)

5. C.K. Lee, R.F. Chaiken, and J.M. Singer, Combustion Science and Technology 20, 59-72 (1979)

6. N. Iliaș, O. Lanchava, and G. Nozadze, Quality - Access to Success, 18, 77-80 (2017)

7. S.N. Bogdanov, S.I. burtsev, O.P. Ivanov, and A.V. Kupriyanova. Kholodilnaia tekhnika (Russian, 1999) 